\title{
"Let's Draw Chocolate Milk Together": Supports and Challenges for Families' Joint Engagement with Artistic Tablet Apps
}

\author{
Samantha W. Bindman \\ sam@foundry10.org \\ foundry 10 \\ Seattle, Washington, USA
}

\author{
Kiley Sobel \\ ksobel@uw.edu \\ The Joan Ganz Cooney Center at \\ Sesame Workshop \\ New York, New York, USA
}

\author{
Sara M. Behbakht \\ sbeh4@uw.edu \\ Human Centered Design \& \\ Engineering, University of \\ Washington \\ Seattle, Washington, USA \\ Mike Scanlon \\ mike@foundry10.org \\ foundry 10 \\ Seattle, Washington, USA
}

\begin{abstract}
Although specific design decisions are known to support Joint Media Engagement (JME; co-play with digital media) it is unclear whether current off-the-shelf tablet experiences are designed with this in mind and whether parents and children are able to engage in JME in practice. As apps that promote artistic creation (i.e., music, drawings) fulfill many extant design recommendations for JME, we observed joint play with two artistic creation apps in a culturally and socioeconomically diverse sample of 20 United States child-mother dyads. Using interaction analysis, we found that in these "ideal" circumstances, families used varying styles of co-engagement, with Co-Creation and Parent Coaching standing out as collaborative arrangements toward which designers and families can strive. However, there were still challenges, with parents often assuming spectator roles despite their apparent intentions. We highlight key challenges to JME plus design supports and parent strategies to help families jointly engage and create with media.
\end{abstract}

\section{CCS CONCEPTS}

- Human-centered computing $\rightarrow$ Empirical studies in HCI; Collaborative interaction; Empirical studies in collaborative and social computing; • Social and professional topics $\rightarrow$ Children.

\section{KEYWORDS}

Joint media engagement; families; children; creativity.

\section{ACM Reference Format:}

Samantha W. Bindman, Kiley Sobel, Sara M. Behbakht, Riddhi A. Divanji, Ella Shahn, and Mike Scanlon. 2021. "Let's Draw Chocolate Milk Together": Supports and Challenges for Families' Joint Engagement with Artistic Tablet Apps. In Interaction Design and Children (IDC '21), June 24-30, 2021, Athens, Greece. ACM, New York, NY, USA, 13 pages. https://doi.org/10.1145/3459990. 3460693

Permission to make digital or hard copies of part or all of this work for personal or classroom use is granted without fee provided that copies are not made or distributed for profit or commercial advantage and that copies bear this notice and the full citation on the first page. Copyrights for third-party components of this work must be honored. For all other uses, contact the owner/author(s).

IDC '21, June 24-30, 2021, Athens, Greece

(c) 2021 Copyright held by the owner/author(s).

ACM ISBN 978-1-4503-8452-0/21/06

https://doi.org/10.1145/3459990.3460693

\section{INTRODUCTION}

Portable touchscreen devices (e.g., smartphones, tablets) are available or rapidly growing in availability in nearly every young child's home around the world [50, 54, 55, 63, 85]. According to parent reports, children in the United States use digital media an average of 2 and a half hours per day [64]. A key form of media use in the family context is joint play, or foint Media Engagement, (JME) between a child and a parent or other caregiver. JME can provide numerous benefits such as enjoyment and learning opportunities, and can bolster relationships, build shared interests, and provide a platform for developing social-emotional skills [29, 36, 70, 71]. Although guidelines have been put forth to foster beneficial joint play experiences, research shows that it can be difficult for parents and children to co-play, for example because of certain design elements such as fast pacing, difficulties with shared positioning, and limited user roles [32].

In this work, we use JME as a lens to examine families' coengagement with digital media. By considering (1) design guidelines that have been offered in previous work to foster JME and (2) what is known about families' typical patterns of play with touch screen apps, we sought to learn more about how such apps are currently supporting children and parents to co-engage in play. If we give families some of the most promising apps we can find for supporting JME, which types of play will we observe, and will any unique forms emerge? Can we then validate the guidelines: will these commercial apps lead to positive joint play experiences, as they are theoretically supposed to? If not, what new strategies can be offered to parents and designers to foster JME and make these interactions more enjoyable and beneficial?

We address these questions through an observational lab study of a diverse sample of 20 American child-mother pairs playing together with two artistic creation apps that fulfill many JME design recommendations. We focus especially on the child's behaviors including their openness to co-play in response to or in light of parent behaviors and app design. The major contributions are a detailed picture of JME with apps that fulfill many JME design recommendations, and suggestions for both designers and parents to better promote families' collaborative engagement with both touchscreen 
apps and interactive media more broadly. In addition, we report on recommendations we found through our formative work, which included gathering and condensing current recommendations for designing media for JME.

\section{RELATED WORK}

\subsection{The Importance of Child-Caregiver Play}

A wealth of research shows that children benefit from everyday play with parents and other caregivers because it is a key context for building and maintaining those crucial relationships [25] Moreover, Vygotsky's sociocultural theory posits that interactions with caregivers and other more skilled partners are a key driver of cognitive development [82]. Adults and more skilled peers provide scaffolding, developmentally appropriate verbal/nonverbal guidance that promotes learning by allowing children to complete tasks they wouldn't be able to complete independently [65, 82]. Scaffolding can include dialogic strategies, verbal support that, for example, encourages the child to make connections between media and the real world or respond in their own words [92]. Scaffolding from parents fosters a variety of child outcomes including language and cognitive skills [78, 79] and self-regulation [20].

Although child-caregiver interactions with digital media may look qualitatively different from other types of child-caregiver play, there is growing evidence that young children get extra benefits from digital media (e.g., digital games, video communication technology, augmented reality) when an adult provides tailored scaffolding $[5,73,74,86,88]$. Due in part to these benefits, the American Association of Pediatrics has recommended co-play for the times when children ages 2-5 years engage with digital media [1] Nonetheless, parents don't always co-play with children, with one study suggesting parents do so about one third of the time when children play with digital apps [15]. Although parents have limited time to play [15, 84], perhaps design could do more to facilitate co-play.

An additional, important facet for which parents need guidance is the extent to which joint play with digital media is child-led as opposed to controlled by adults. Self-Determination Theory states that one of children's most important psychological needs, like adults, is the need for autonomy (i.e., the feeling that one's actions are driven by intrinsic motivation and value as opposed to internal or external pressures) [17]. Caregivers can support children's autonomy by recognizing their needs and desires, allowing them to solve problems independently, and providing them with choices [27]. Together, these theoretical perspectives suggest that co-play is both enjoyable and beneficial when it balances tailored scaffolding with the child's need for autonomy. In the current study, we examined the extent to which families' play was child- or adult-led and explored whether this facet of play was related to the types of JME that occurred.

We focus on child-parent interactions with 4- and 5-year-old children. By this age, children are able to learn from digital media independently but benefit from parent mediation [53]. Parent scaffolding is also a key factor in development at this age, and can be important for children's success as they enter formal school in kindergarten [57].

\subsection{Design for Joint Media Engagement}

Joint Media Engagement $[75,77]$ is a theoretical framework that is (1) descriptive of the ways people use media together-which includes viewing, playing, searching, reading, and creating with either digital or traditional media-and (2) prescriptive both (a) in guiding designers with the creation of media experiences that support co-use and (b) in helping families engage in collaborative and enjoyable experiences with media that support children's development. Based on a convening about this topic and research in this area, Takeuchi and Stevens published The New Coviewing [77], where they specifically put forth design recommendations for digital media to facilitate JME that is beneficial, active, and enjoyable for all participants. Although these foundational guidelines were published in 2011 before tablets became widely used in families with young children, they are a highly relevant source in today's technology and digital media landscape [73]. Some key recommendations they offer are to design for multiple user roles, to allow for co-creation of new artifacts or understandings, to provide content that is engaging for users in different age groups, and to encourage users to make connections between the media and their own experiences [77]. Reviews of educational apps on the market for children suggest that few are designed for JME [11, 34].

Within the IDC and HCI communities, there has been a growing focus on families and technology (e.g., see [40, 44, 87]), with significant research on how to support child-parent joint media engagement. This work in family digital cooperation and collaboration has included remote communication and play (e.g., [14, 24, 83, 86, 88]), co-located joint play and gaming (e.g., $[2,10,32,61,69,71,73,90])$, and reading together in person with e-books or across distances (e.g., $[13,45-47,59,62,81])$. For example, in one study by Hiniker and colleagues [32], families brought their own devices to a lab setting and played with apps they use at home. Design aspects that challenged JME included parents struggling to find roles to participate in tablet play, as compared to play with other toys, and the pacing of apps demanding constant attention and hindering child-parent engagement. (See Ewin et al. [21] for a review of 27 papers across media studies, child development, and HCI that focus on the impacts of joint media engagement on families and their interactions.)

Additionally, IDC and HCI researchers have focused on the ways that multimedia technology can support children's creativity through art production, like music creation (e.g., [3, 4, 30, 60]), drawing (e.g., [35, 67]), and storytelling (which often utilizes the former) (e.g., [19, 22, 26, 39, 41, 66]) (see [38] for a review). A small subset of this work has looked at the potential of technology to support collaborative art making between children and adult caregivers. For example, StoryKit is a mobile application for collaborative story creation, which Bonsignore et al. co-designed and studied with children, parents, and grandparents $[9,58]$. They found that the multimedia support was especially important for creativity and collaboration; intergenerational family dyads created rich electronic 
storybooks together through text entry, sound recordings of animals, photographs of animals, and drawings. The audio recording feature specifically was supportive of non-verbal children making stories with their parents. Regarding families' joint music creation, Sound Happening is an interactive installation, exhibited at the Children's Museum of Pittsburgh, in which children and caregivers move colored balls around the space to make music [49]. In their case study, Long et al. [49] suggest that the system supported children and adults in co-play due to its embodied interaction paradigm, cultural framing as a ball game, and its open-endedness allowing for (adult and child) age-appropriate engagement.

This related research serves as a strong basis for our current work, which draws and builds on the literature in terms of our focus on the potential of co-creation as a form of joint engagement. Importantly, following Takeuchi and Stevens's [77] call for research into "the qualities of media design and deliberate use that encourage productive JME" (p. 55) and Ewin et al.'s [21] recent recommendation that further research be conducted into how devices, apps, and other media content can foster parent-child JME, we use joint media engagement as a theoretical lens for examining collaborative artistic app engagement between children and parents.

\section{PRELIMINARY WORK}

Before we could examine how children and parents engage with digital media together, we needed to determine which applications would be best for our observational study. This process involved reviewing current guidelines on JME and on children's apps that promote learning and positive development, and then evaluating children's apps according to these guidelines. Through this process, we generated (1) a resource that condenses recommendations about technology for JME into one list and (2) a broad assessment of which currently available applications satisfy such criteria.

Across the related work we described above, we gathered eight sources that explicitly enumerate what specific design features make digital media supportive of young children's learning and/or productive for young children and parents' joint media engagement (with a focus on digital play, in particular) $[12,32,34,50,71,73$, $77,80]$. Two researchers reviewed these sources to see where their enumerations of design features overlapped and where they did not; they then iteratively and inductively condensed the over 30 different design characteristics listed across all of the sources into one list of 16 distinct features that influence whether digital media will support learning and JME (See Table 1).

Our next step involved examining tablet-based content to see how design recommendations for JME and learning are instantiated in the current app marketplace. Exploring the marketplace in this way enabled us to not only (1) determine if and how any off-the-shelf apps might support JME, but also (2) choose commercial apps for our lab study that would allow us to observe how families engage in practice with those that best satisfy the principles. We looked at online parenting websites (e.g., parentmap.com, parents.com), Common Sense Media app reviews, and Apple's App Store to find applications that adhered to five baseline requirements; these applications had to be specifically targeted at or appropriate for children under 6 (Table 1: 1, 2), free of any obvious distractions or pop-ups (Table 1: 3), interactive (Table 1: 4), and user-paced (Table 1: 5). Through initial reviews of the apps, we decided not to evaluate whether or not the apps fit into family cultures, values, or norms (Table 1: 16), as it was beyond the scope of the study to examine this content in relation to specific families or groups of families.

The next step was to evaluate whether the remaining 10 JME criteria were satisfied in the application (e.g., Does/could the app support or encourage shared positioning?) and, if so, how (e.g., How does the app support shared positioning? How might both partners be able to participate? Are there multi-touch capabilities?). We found 22 applications to evaluate, which generally fell into two main categories: exploratory games (e.g., Toca Nature, Daniel Tiger's Neighborhood, Alien Assignment) and "creativity" apps (i.e., creating stories, music, pictures) (e.g., Lipa Theater, Singing Fingers, Loopimal, Relationshapes). We also included a few open-ended creative applications that weren't explicitly targeted at children but were open-ended enough that an adult could scaffold them for children (e.g., Keezy, Soundrop, Bloom).

Two researchers played through the applications to determine whether each of the 10 criteria existed in the app and how they were instantiated. We found the most interesting variation in opportunities and points of entry for joint media engagement in open-ended artistic creation apps. Unlike exploratory applications, these creativity apps-which were grounded in constructivist and constructionist theories of learning [31,56] (Table 1: 6)-have the potential for both partners to personalize the experience. Rather than prescribing explicit interactions, these applications allow partners to enjoy the experience (Table 1: 7), create together (Table 1: 8), contribute to the creation in their own ways (Table 1: 9, 10), connect their creations to the real world (Table 1: 11), and talk as they create (Table 1: 12).

At the same time, none of these applications had explicit supports for parents to scaffold their child's experience (Table 1: 13); instead, parents must find ways to support children to ensure that their child can develop through use (Table 1: 14). And while the applications provided contingent feedback to users (i.e., inputs resulted in visual or auditory results) (Table 1:15), adults would have to provide other types of contingent feedback to give children more meaningful responses to what they were creating. Ultimately, we chose Pitch Painter [76], a music creation application, and Sago Mini Doodlecast [68], a drawing and storytelling application, as the two artistic creation apps for our lab study (Figure 1).

\section{METHODS}

\subsection{Participants}

Twenty child-mother pairs participated in the study (F1-F20) (see Table 2 for demographic information). All participants were proficient in English and the study was conducted in English, although participants occasionally spoke in their home languages when playing together. Translation by a native or fluent speaker was made when families spoke other languages, particularly when it was needed to follow the complete interaction. Families were asked whether they had played either of the apps before the study. One parent had played Pitch Painter but had never played it with her child. 
Table 1: 16 design features that promote joint media engagement (JME).

$\begin{array}{ll}1 & \text { Be child interest-driven } \\ 2 & \text { Be developmentally appropriate } \\ 3 & \text { Be free from distractions like pop-ups } \\ 4 & \text { Be interactive } \\ 5 & \text { Have simple controls / be user-paced } \\ 6 & \text { Have theoretical grounding in the learning } \\ & \text { sciences } \\ 7 & \text { Include multiple planes of engagement so } \\ & \text { all partners enjoy the experience }\end{array}$

8 Support co-creation

9 Encourage shared positioning

10 Support different roles for partners

11 Connect to the real world

12 Promote joint attention, collaboration, and dialogic inquiry

13 Provide structure for adult scaffolding or self-exploration

14 Allow child to grow/develop through use

15 Provide contingent, meaningful feedback

16 Fit into family culture, values, and norms

Table 2: Participant demographics ( ${ }^{*}$ Age notation: \# years, \# months = \#y\#m); ${ }^{*}$ Other languages: Arabic, Hindi, Marathi, \& Swahili)

$\begin{array}{lllllllll}\text { Women/Mothers } & 20 & (100 \%) & \text { Child race/ethnicity } & & \text { Income \$100k+ } & 6 & (30 \%) \\ \text { Parent age } & 30-41 \text { years } & (\mathrm{M}=34) & \text { Hispanic/Latino } & 8 & (40 \%) & \mathbf{\$ 8 0 , 0 0 1 - 1 0 0 k} & 3 & (15 \%) \\ \text { Married } & 18 & (90 \%) & \text { White } & 5 & (25 \%) & \mathbf{\$ 6 0 , 0 0 1 - 8 0 k} & 2 & (10 \%) \\ \text { Non-married } & 2 & (10 \%) & \text { Asian } & 2 & (10 \%) & \mathbf{\$ 4 0 , 0 0 1 - 6 0 k} & 2 & (10 \%) \\ \text { Girls } & 11 & (55 \%) & \text { Black } & 1 & (5 \%) & \mathbf{\$ 2 0 , 0 0 1 - 4 0 k} & 3 & (15 \%) \\ \text { Boys } & 9 & (45 \%) & \text { Native American } & 1 & (5 \%) & \mathbf{\$ 2 0 k} \text { or less } & 2 & (10 \%) \\ \text { Child age* } & 4 \mathrm{y} 4 \mathrm{~m}-5 \mathrm{y} 9 \mathrm{~m}) & (\mathrm{M}=5 \mathrm{y} 1 \mathrm{~m}) & \text { Multiracial } & 1 & (5 \%) & \text { No response } & 2 & (10 \%) \\ \text { Parent race/ethn. } & & & \text { No response } & 2 & (10 \%) & \text { Post-grad degree } & 6 & (30 \%) \\ \text { Hispanic/Latina } & 10 & (50 \%) & \text { Language(s) at home } & & \text { 4-year degree } & 6 & (30 \%) \\ \text { White } & 6 & (30 \%) & \text { Spanish } & 7 & (35 \%) & \text { 2-year degree } & 3 & (15 \%) \\ \text { Asian } & 2 & (10 \%) & \text { Spanish \& English } & 4 & (20 \%) & \text { Some college } & 1 & (5 \%) \\ \text { Black } & 1 & (5 \%) & \text { English } & 5 & (25 \%) & \text { High school deg. } & 3 & (15 \%) \\ \text { No response } & 1 & (5 \%) & \text { Other** } & 5 & (25 \%) & \text { Less than H.S. } & 1 & (5 \%)\end{array}$

\subsection{Materials}

Families played with the apps on a 9.7 inch Apple iPad in a soft plastic case. Pitch Painter [76] is an open-ended music composition application in which drawing with different colors and corresponding instruments on a grid creates music that can be played back in different ways (e.g., reversed, upside-down) (Figure 1, left). Doodlecast [68] is an open-ended drawing application that provides options for starting via general prompts, a blank page, or a photograph taken by the user. The app includes a color palette and drawing tools (Figure 1, right). The drawing process is recorded, with sound, for playback and can be used for creating a message or story.

\subsection{Procedures}

Data collection took place primarily in two Play and Learn centers, as well as quiet meeting rooms in two public libraries and an office, all of which parents indicated were convenient study locations. A couch or folding double camping chair and small table were provided (Figure 2). After obtaining consent and assent, researchers introduced three play tasks, each of which lasted eight minutes. Play was recorded with two digital cameras placed in front and to the side of families, and iPad play was recorded via screen capture. In the first task (not analyzed here), the parent and the child were asked to make a drawing together on a whiteboard. In the second and third tasks, the parent and the child were instructed to play each of the apps (DoodleCast and Pitch Painter) together on an iPad.
A researcher briefly explained how each app worked and pointed out the main features. Half of the families played Pitch Painter first and half played DoodleCast first. Each family received $\$ 40$ in cash or cash card, and the child received a small toy.

\subsection{Data Analysis}

We used video-based interaction analysis $[18,43]$ to analyze the complex engagements and interactions between parents, children, and the apps. Researchers watched and content logged each of the video recordings of the two app play tasks by transcribing events, interaction sequences, and key dialogue and making analytical and observational notes.

Using emergent themes, JME guidelines, and related literature as a theoretical guide, four researchers then iteratively coded the transcriptions through a joint inductive/deductive approach [16]. Our analytic units focused on interactions between child and parent, between child and app, and between parent and app (e.g., gesture, orientation, talk, etc.). Over frequent collaborative meetings, the team reviewed the content logs that built on emerging findings, discussed codes and themes, and revised the coding framework several times. Interaction types observed in prior work on parentchild interactions (e.g., [32, 52, 91]) formed the basis for the coding system and additional types were added to capture interactions that were particular to the context of families using joint artistic creation apps together. This analytical process resulted in 8 major codes and 32 sub-codes covering roles and behaviors of parents and 


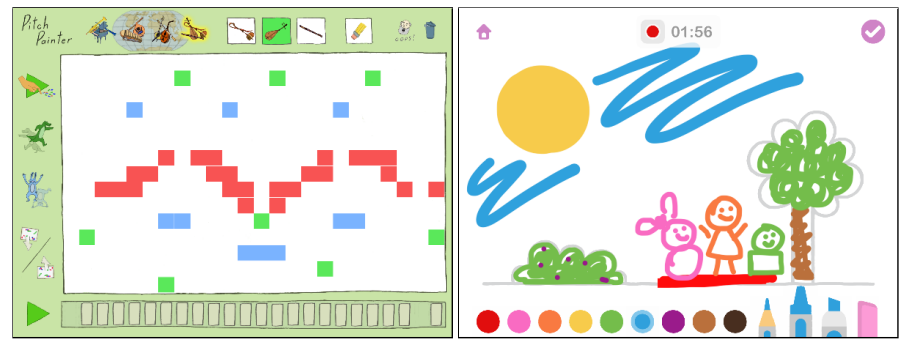

Figure 1: Screenshots from Pitch Painter (left) and Doodlecast (right, with prompt "What's in the park?")

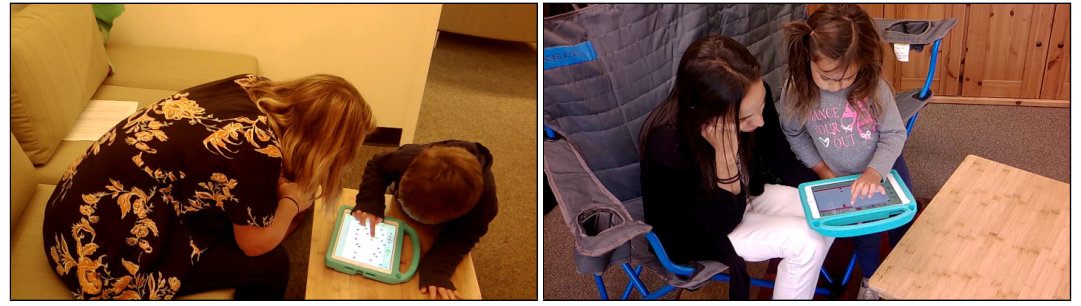

Figure 2: Sample arrangements that families used to play with the provided materials.

children, app design features that shape co-play, and other instantiations of JME (e.g., code: parent as coach; sub-codes: structuring, teaching, technical assistance). The codes captured common forms of play as well as some types that were less recurrent but which indicate possible forms that could be fostered by design choices. In the results, we review overarching patterns of play with select illustrative transcripts, which use conventions from Jefferson [42]. All names are pseudonyms with superscripts indicating mother (M), daughter (D), or son (S).

\section{RESULTS}

Through our analysis, we characterized patterns in families' app play with particular attention to the child's openness to collaboration, noting parent behaviors and design features that appeared to facilitate or hinder joint engagement. In the following sections, we describe these patterns ranging from more collaborative forms of interaction (e.g., Co-Creation, Watching Playback Together) to less (e.g., Parent Spectating, Parallel Play), distinguishing several types of $\mathrm{Co}-\mathrm{Creation}$ and Parent Coaching along with their possible antecedents.

\subsection{Watching Playback Together}

Observing families' use of the artistic creation apps revealed that watching playback together was a consistent source of playful, affectionate joint engagement whether families were watching the recording of their drawing (Doodlecast) or playing their musical composition (Pitch Painter). For example, when one child (F3) played her creation in Pitch Painter, her mother danced to the music. We also observed children watching their parents' reaction to playing back their work. An example of this occurred when F7 played Pitch Painter:

\author{
Nina $^{D}$ : Let me try to do it ((Draws on the screen)) \\ Bianca $^{M}$ : ((Presses the side playback button; both mom and \\ child watch themselves erasing the old picture)) \\ Look, what did you do? \\ $\mathrm{Nina}^{D}$ : I want to do it again. ((Holds mom's hand back)) I \\ want to see the whole thing. \\ Bianca $^{M}$ : Okay, I won't touch the screen. \\ Nina $^{D}: \quad(($ Presses play. Grabs mom's hand excitedly when \\ she sees replay. Laughs, looks at mom))
}

Exploring playback features and watching their own creations sparked many affectionate moments among the families. Playback was one of very few features that prompted children to share their attention with their parents.

\subsection{Co-Creation}

The most jointly active and participatory form of play we saw was when families co-created; that is, when parents and children worked collaboratively to make something new. Importantly, co-creation was not noted in previous work where families used a variety of apps they usually play at home [32]. During Co-Creation, parents and children demonstrated joint attention and participation with the same artifact or task within the app. Our analysis revealed that $\mathrm{Co}$-Creation took several forms that ranged along a spectrum from Parent-Led, Co-Led, and Child-Led play. In general, children were more open to parent participation when it followed the child's agenda for the activity in some way.

5.2.1 Parent-Led Co-Creation. In line with prior studies (e.g., [32]) and the fact that tablets are individually-sized, it's no surprise that children in our study had difficulty sharing the device. When families successfully shared the device to engage in co-creation, it was nearly always because the parent established shared positioning (i.e., Parent-Led Co-Creation). For example, one mother (F14) put 
her arm around the child, who had the iPad on his lap. Another mother held the iPad in a way that allowed her son to play on it while the iPad remained in front of her (F9). Very rarely did children prompt shared control. For instance, while one dyad (F7) played Doodlecast, the mother facilitated turn-taking, which, although frustrating for the child, later proved to be a catalyst for shared positioning:

$$
\begin{aligned}
& \text { Nina }^{D}: \quad((\text { Tries to pull her mom's finger off the iPad screen } \\
& \text { Nina } \left.\left.{ }^{D} \text { : ((Holds mom's hand so mom can't draw anymore }\right)\right) \text { I }
\end{aligned}
$$

As the interaction continued, the mother used playfulness and persisted with turn-taking. Although Nina ${ }^{D}$ complied with this form of joint engagement, she continued to appear impatient as she sighed frustratingly while she waited for her turn. Her mother let Nina ${ }^{D}$ know it was her turn but teased her by continuing to draw. In response, the child continually grabbed her mother's hands. After responding what she wanted to draw and doing so, $\mathrm{Nina}^{D}$ flopped onto the couch. Throughout this interaction, the child followed her mother's lead and yielded when it was her mother's turn. At the same time, it was difficult for the eager child to wait her turn, illustrating one of the main difficulties with child-parent collaboration with tablet apps.

Similarly, the parents' attempts at setting the agenda for the activity sometimes seemed to create conflict over control, which happened when F15 played Doodlecast:

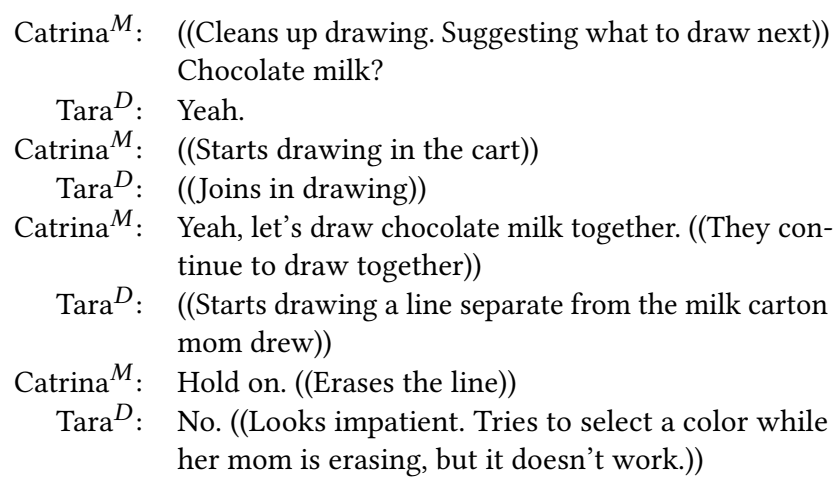

In moments like this, we saw that parents' attempts to control the creation process were met with child resistance.

5.2.2 Co-Planning. Sometimes being co-creators involved joint planning, decision-making, and action related to what and how to create. Co-planning seemed to be primarily initiated by the parent, for example when one parent (F5) drew in Doodlecast while consulting her child at each decision point about what to draw ("A cloud?") and what color and thickness of line to use. In F15, both the mother and child planned what they were going to draw and contributed to the drawing in different yet equitable ways:

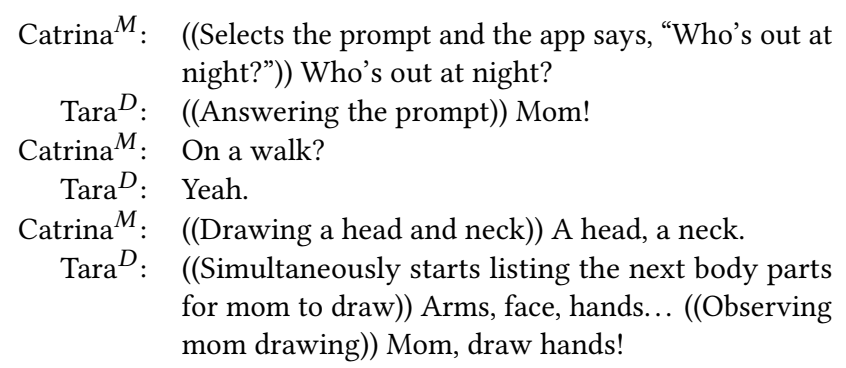

Here, the mother invited the child to make decisions about what they would draw, and the child appeared excited by her mother's approach to collaboration.

5.2.3 Parent plays a supporting role in child's creation. Although children were often reluctant to share the device and app play, parents found creative ways to get involved. For example, in F11 the parent participated by being a "cleaner-upper" or fixing the child's "mistakes" in Doodlecast using the erase feature:

Sejal $^{M}: \quad(($ Selects eraser. In Hindi)) Can I clean up your beans a little? You've kind of scattered them everywhere. ((Begins erasing))

$\mathrm{Ami}^{D}: \quad(($ Laughs $))$

Sejal $^{M}$ : Mom is doing clean up all the time. ((Begins drawing more beans)) I want to add more beans to your plate because it's healthy for you.

$\mathrm{Ami}^{D}: \quad(($ Observes and then physically acts like she is eating the beans))

As another example, in F13, when the child $\mathrm{Joe}^{S}$ had just finished drawing a Minecraft character using the Pitch Painter app, the mother added to the creation. After exclaiming, "Let's try something!" she changed the instrument and drew eyes and a smiley face on her son's character. In response, Joe ${ }^{S}$ gasped excitedly and smiled, looking at the tablet, and then his mother did the same and laughed. In these examples, parents assisted the children with carrying out their goals, and again children seemed to be open to this kind of partnership in the activity.

5.2.4 Child-Directed Co-Creation. Another important category within Co-Creation is when the child directed joint play and actively structured the parent's involvement. When Child-Directed Co-Creation occurred, the child invited the parent to participate equally in the play or creation process. In one case, while F19 played with Doodlecast together, the child Sofie ${ }^{D}$ took on a leadership role, asking a question in a way that a parent might ("Which color do you want to use? Green? It's your favorite color."), and her mother followed her directions (drawing green grass). In a similar case, F7 played Pitch Painter with the child $\mathrm{Nina}^{D}$ leading the creation; after the mother said it was her own turn and selected an instrument, she and her daughter drew with the trumpet at the same time. However, Nina ${ }^{D}$ chose and switched the instrument the next two times, after 
which she and her mother drew together with both instruments. Here, the child took the leadership role smoothly from the mother and began directing her participation in much the same way her mother had originally structured the play.

Child-Directed Co-Creation could also be quite playful and less intentional in terms of creating a certain product. For example, several children attempted to fill the whole drawing space in the Pitch Painter app. The parent in F16 even adopted her child's goal in a playful way; when she and her daughter were drawing on the screen, they both painted faster and faster, back and forth until they filled up the entire screen and her daughter then announced, "It's filled!" Another example of similar, playful Co-Creation happened when the mom and son in F13 played with Pitch Painter:

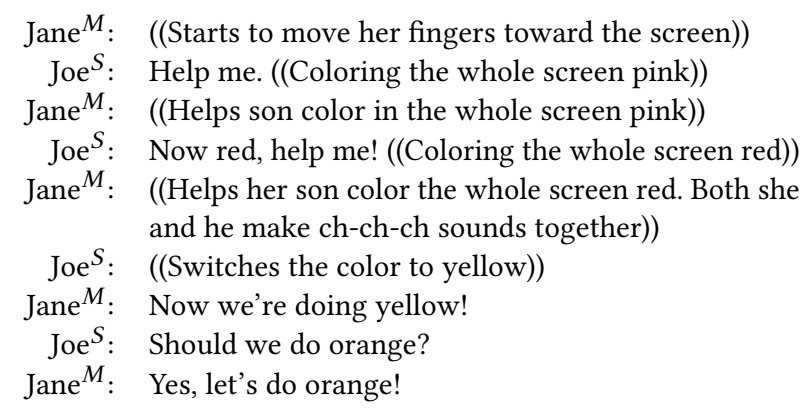

This is one of several examples of times when a parent's willingness to follow the child's agenda, even if it didn't result in a product that was explicitly prompted by the app, seemed to boost the child's engagement with the parent and also reduce struggles for control of the device.

\subsection{Parent Coaching}

Another common arrangement was for the child to play with the apps while the parent made suggestions and provided guidance without playing themselves. Parents frequently tried to play directly with the apps but children were not often open to sharing. We saw three different coaching strategies from parents, drawn from prior work (e.g.,, $[28,50,89]$ ), with most parents using multiple coaching strategies in any given interaction: structuring, cognitive support, and technical support. Building on prior work's findings, we focused on identifying times when the child was receptive to parent involvement or resisted/ignored parent coaching. Two additional strategies, boundary crossing and playful coaching, seemed to facilitate these interactions.

5.3.1 Structuring. Structuring included both verbal or nonverbal suggestions or commands from the parent, including drawing the child's attention to different parts of the task, keeping the child on task, and providing ideas for what to draw or make next [28]. For instance, Joe ${ }^{S}$ (F13) had selected the prompt "What's in the box?" in Doodlecast and his mother used structuring to remind him of the prompt. She asked him, "What's going to be in your box?" but he did not respond and proceeded to color the entire page brown. When it was completely filled in, she asked him if he wanted to draw something else, saying, "What would you like to see in a box?" He answered, "A freight train." As shown in this example, structuring was a parent strategy that could be met with both resistance and cooperation from children.

5.3.2 Cognitive support. Cognitive support involved providing the child with new information, such as explaining how the app worked or teaching the child new conceptual information (e.g., colors, instruments, or how to draw things) [52, 89]. Sometimes, parents physically guided children's hands to teach them something, but usually teaching was verbal. Both the Doodlecast prompts (e.g., "What's in the shopping cart?") and the Pitch Painter playback features provided opportunities for parents to teach.

For example, one parent (F9) demonstrated a complex musical concept in Pitch Painter. To highlight for her child Mirabel $^{D}$ the way the app plays the notes horizontally from left to right, the mother explained, "The music is a line," and then drew and played a vertical and a horizontal line. She reinforced the differences by directing Mirabel ${ }^{D}$ 's attention ("See, the music is going...") and affirming her child grasped the concept ("Do you understand?).

5.3.3 Technical assistance. Similar to teaching, technical assistance refers to times when the parent helped or taught the child to use the iPad or app [52, 89]. For example, sometimes parents explained which button to press (either because the child asked for help or because the parent saw the child struggling). This happened while F14 played Pitch Painter:

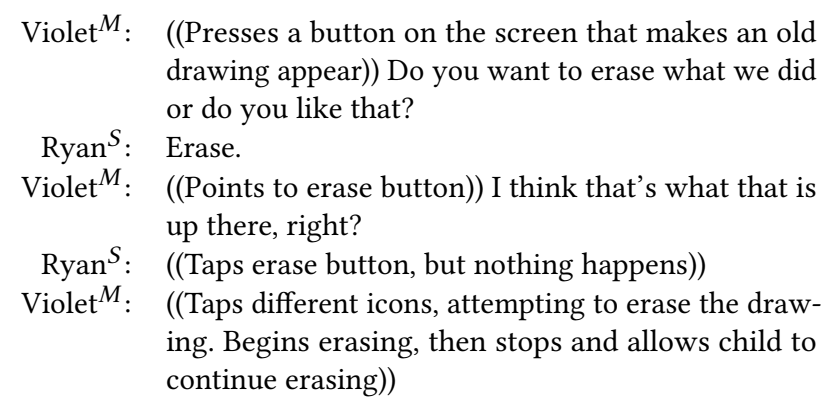

In another case with the same dyad (F14), the parent used the Pitch Painter features as an opportunity to explore together. Although Ryan $^{S}$ was engrossed in filling the entire screen in with one color, he was open to pausing his work to try different features. Specifically, the mother asked, "What do those buttons do?" while pointing at the sidebar. Ryan ${ }^{S}$ then selected some of the buttons, triggering playback; they listened together, and the mom described the functions of the sidebar buttons verbally. Both of these examples demonstrate how features provided opportunities for parents to teach information about the app in ways that promoted joint engagement as opposed to struggles for control.

5.3.4 Boundary crossing. Boundary crossing is when a family explicitly relates their play to another time or setting in the past, present, or future [77]. We observed that boundary crossing was another (often successful) entry point for children to become interested in engaging with the parent. Nearly all instances of boundary crossing were sparked by a question that the parent asked of the child.

Certain app features gave parents opportunities to engage their child in crossing boundaries between the app and other experiences. 
Doodlecast provided this explicitly with its drawing prompts about everyday life (e.g., "What is in the shopping cart?"). F15 chose this prompt, and the mother asked $\operatorname{Tara}^{D}$ to think about their own experiences: "What other things do we buy at the store?" Tara ${ }^{D}$ answered that they buy apples, and then more specifically "red" ones, after the mother asked what color. Reinforcing this response, the mother added, "Really? Oh yeah, we do buy red apples."

In Doodlecast, the 'blank page' option also allowed families to use the iPad like they would a blank paper in real life, i.e., to write and practice 'sight words' or practice the alphabet. For example, F3 used this feature to practice reading. The child began practicing writing and the mother said, "There's a word you've been learning" and wrote the word 'you,' which her daughter read. The mother then said, "Oh, we could practice our sight words here."

The Pitch Painter app also facilitated boundary crossing by providing a 'blank slate' for creation. However, the grid feature on the blank page influenced the interactions. Some families enjoyed drawing everyday objects or words and seeing what they sounded like when played back as music. For example, in F19 Sofie ${ }^{D}$ was intrigued when she saw her mother use Pitch Painter to draw her name and listened eagerly as her mother played it back as music. Children very often were interested in parents' prompts to cross boundaries between the apps and their own names or experiences.

5.3.5 Using playfulness to coach. Playfulness through being silly or affectionate was one way that parents tried to get children to be more receptive to a parent's coaching role. Playfulness seemed to be one of the most effective strategies when the child was resistant to the parent's involvement in the app play. Sometimes it also led to co-creation or co-play.

For example, in an effort to engage with the child, sometimes parents would make a game out of the task. As F5 played Doodlecast, the mother switched the thickness of the drawing tool back and forth from thick to thin as Yamile ${ }^{D}$ was drawing, which the child seemed to enjoy. Several parents in our study tried to get their child to stay on the prompt chosen in Doodlecast, but instead this mother played with the child first and then asked the child to do the task.

Sometimes parents would use playfulness to coach (e.g., drawing something silly to make the child laugh). Other times, parents used this tactic when the child refused to give up physical control of the iPad. For example, one mother (F7) hugged her child when the child blocked her from touching the iPad, and another mom (F18) gently grabbed the child's hand and kissed it in order to get physical access to the iPad.

\subsection{Parent Spectating while Child Plays}

In line with prior work (e.g., [32, 90]), a more common arrangement was the child playing or creating with an app while the parent watched attentively without being actively involved in the play. While parents nearly always attempted to actively participate with their child (e.g., touch the screen, make suggestions, create), parents often took on a spectator role after the child ignored or resisted their involvement or physically took control of the device. Subsequently, the parent pulled back or gave up on co-playing, sometimes early on in the interaction.

For instance, in F17's first app play session, the mother tried to be involved by helping her child Istas ${ }^{D}$ choose a drawing prompt in
Doodlecast. Yet, Istas $^{D}$ took the iPad away, tapped quickly through the instructions, and ignored what her mother was saying. Her mother didn't try to stop her. As the interaction continued $\operatorname{Istas}^{D}$ resisted help from her mother, and when the eight-minute session ended, the mother had taken on the role of spectator. Similarly, in the beginning of F20's play session with Pitch Painter, the mother was touching the screen and pressing the playback button. However, within one minute, the child Tane ${ }^{S}$ was controlling all of the drawing and playback. Two minutes later the mother said, "Can I try?" and, "Mommy's turn," but Tane ${ }^{S}$ said, "No, wait," and drew another shape. It was only after another full minute that the child gave the device to his mother to play.

In line with this idea, a frequent interaction occurred when parents took on a spectator role after their child took physical control of the device. A representative example happened during F7's play when $\mathrm{Nina}^{D}$ physically blocked her mother with her body, exclaiming "I want to do it by myself!" Still, when the parent used playfulness and affection to try to get involved, by hugging her daughter and asking, "You're not gonna let me play or what?" $\mathrm{Nina}^{D}$ ignored her and the mother continued to only watch. We observed similar interactions where parents began the play session by touching the screen and engaging with features, but ended up watching despite attempts to stay involved.

\subsection{Parallel Play: Engaging Side by Side}

We also observed interactions in which parents and children played next to, but not with, each other. For example, when F5 was playing with Pitch Painter, the child focused on drawing while her mother explored the playback options toolbar on the side of the screen:

$\begin{aligned} \text { Gabriela }^{M}: & \begin{array}{l}((\text { While child draws })) \text { Okay, I'm gonna try ((Starts } \\ \text { pressing some side features })) \\ \text { Yamile }\end{array} \\ & \begin{array}{l}(\text { Adds some lines to the screen while mom experi- } \\ \text { ments })) \\ ((\text { Selects a feature that plays back the screen re- }\end{array} \\ \text { Gabriela }^{M}: & \text { versed })) \\ \text { Yamile }^{D}: & ((\text { Holds her hands up, surprised })) \\ \text { Gabriela }^{M}: & \text { Ohhh! }\end{aligned}$

In these interactions, the child and mother engaged with different aspects of the app that interested them, showing that these apps provided points of engagement for both parents and children.

\section{DISCUSSION}

This study examined whether and how contemporary touchscreen app design supports joint media engagement for young children and their parents. Using apps that were theoretically most supportive of JME, we explored (1) which types of joint play would occur among families and whether any novel forms would emerge; and (2) whether design features suggested to support JME actually lead to enjoyable, developmentally beneficial joint play.

Under this theoretical "best case scenario" for JME, we observed some of the common play arrangements seen in prior work (e.g., Parent Coaching and Parent Spectating). At the same time, we also saw many instances of families engaging in Co-Creation of various forms, which is a less explored pattern by related research 
(i.e., building on $[9,58])$. It appeared that, when instructed to play together with these artistic creation apps, parents aimed for either creating something together or offering coaching and suggestions while the child played. However, despite these apps being relatively conducive to JME in theory (e.g., user-paced with potential for multiple user roles), children tended to resist sharing the device and many parents fell into the role of passive spectator while the child played. Parents' role in the interaction seemed to depend largely on whether children were open to their involvement, and we identified some contexts in which this was more likely to happen. We also observed several design features and parent strategies that allowed parents to engage with their children and the app so that Co-Creation or Parent Coaching could happen.

\subsection{Design Criteria for JME \& Tablet Apps}

Our preliminary work yielded 16 key design criteria for evaluating and developing technologies such as touchscreen apps for JME. In the current landscape, some defining features of apps that promote (as opposed to hinder) JME are that they are user-paced, allowing children time to pay attention to the parent, and also conducive to multiple user roles (Table 1). These criteria highlight the potential of technology that promotes creativity as a rich context for both child learning and joint engagement with parents, thus confirming why this genre of app is particularly useful for JME [38, 77]. Case studies have documented that families creating digital media together (e.g., taking photos, producing their own hosted videos) can further children's learning about their interests, providing opportunities for boundary crossing between home, school, and community contexts $[6,48]$. In a similar vein, families have used mobile storytelling apps to create meaningful stories about their shared experiences $[9,58]$, and they have produced music together in embodied, developmentally appropriate ways with tangibles [49].

Building on this work, our exploration of design recommendations and features under the lens of JME also illustrates that open-ended apps that promote creation of art such as music or drawings stand out because they support learning through constructivist and constructionist approaches [31, 37, 56] and allow for a wealth of flexible roles for two partners working together. Additionally, they offer opportunities for participants of different ages to enjoy different aspects of the experience, create together, use the touchscreen device at the same time, and draw connections between the app and their past, present, or future experiences, all while discussing their creations. An added advantage of the particular apps we chose to study (Pitch Painter and Doodlecast) is that they allow users to listen to or watch their creations (similar to StoryKit $[9,58])$. Our interaction analysis showed that the playback features prompted numerous affectionate and playful interactions between parents and children. Although not feasible for all app types, this feature can make a big difference in families' joint play experience.

Moreover, we found that very few, if any, currently available apps support caregivers in scaffolding the experience for their children, nor do they provide tailored feedback about their work. In the case of artistic creation apps, this lack of support may be an advantage because it allows the apps to fit into families' diverse cultures (another recommendation for JME), but it also places more responsibility on the parent.

Finally, we sometimes observed both family members playing alongside one another without reacting to what the other was doing (i.e., parallel play). This is another example of how apps that allow for artistic creation provide different planes of engagement that allow for simultaneous play more readily than other types of apps observed in prior work [32]. Although parallel play did not occur enough for us to further investigate, it could include enjoyable conversation unrelated to the app and even lead to more interactive forms of joint engagement. Nonetheless, these examples of parallel play suggest that even when apps prove engaging for both parents and children, facilitating more collaborative forms of play can still be a challenge. These apps rely heavily on the participants, especially parents, to make sure that joint play happens. While studies have looked at how design can scaffold such parental scaffolding (e.g., [23, 33, 59, 72-74]), it is an open question whether apps can or should do more to actually enforce collaboration between children and parents and what consequences such efforts would have on families' play.

\subsection{Co-Creation: Favorable Conditions for Parent- \& Child-Led Play}

One of the most common ways that families approached the task of playing together with the two artistic creation apps was to work collaboratively to make music or drawings. Although Co-Creation has been studied and designed for in the past, prior work did not identify different types of Co-Creation and connect them with specific design recommendations and parent strategies. Moreover, this type of interaction has not been widely observed in studies with other kinds of industry-developed tablet applications, like exploratory apps and instructional, goal-oriented games [32, 73, $74,90]$. This is one type of play on which JME-oriented apps can capitalize.

We observed several different types of Co-Creation, suggesting that this type of play is flexible in allowing both parents and children to take the lead or alternatively, to co-lead. Parent-led Co-Creation was particularly successful (in terms of minimizing conflict over control of the device) when parents used the strategy of promoting and structuring turn-taking and shared positioning of the device. Apps could support these behaviors by, as we mentioned above, providing "scaffolds to scaffold" [77], like explicitly prompting two users to take turns or hold the device in a shared position. In line with Self-Determination Theory [17, 27], parent scaffolding that promoted the child's agenda for the activity seemed to boost children's willingness to allow the parent to participate. Sometimes parents and children made decisions and created together as equal partners, an arrangement that parents can facilitate. In this same vein, we observed two variations on Child-Led Co-Creation. Parents either assisted or complemented the child's creation process (e.g., helping the child with their drawing by following their work with the eraser to clean up mistakes) or followed the child's lead in creation, often playing or making something that was not originally intended by the app design (e.g., filling in the entire drawing space with one color). Sometimes children even took on a parent-like role, prompting the parent with questions and suggestions. It is not 
surprising that child-led play facilitates joint play; it is a principle of JME design (Table 1: 1; [77]). Providing explicit decision points (e.g., choosing among drawing prompts in Doodlecast or instruments in Pitch Painter) that parents can leave for children is one way that apps can give children autonomy.

\subsection{Parent Coaching: Assistance with Challenges \& Making Connections to Experiences}

Replicating results of related studies [28, 32, 52, 89], another common way families approached the task of playing together with artistic creation apps was for the parent to coach while the child played. Parents' scaffolding fell into categories produced in prior research (structure [28], cognitive support [89], and technical support $[7,50,51,89])$. One approach parents can take is to provide support with aspects of the app that are challenging for the child. Children often stopped playing and listened to parents when parents offered technical assistance with the device or app features that supported children's goals for their play. With this type of assistance children can accomplish tasks that are too challenging to tackle alone (e.g., learning about the association between colors and instruments or the various replay options in the sidebar of Pitch Painter) [82]. Any features or tasks that prompt children to seek assistance can facilitate joint play, whether they be non-transparent features to explore together, a challenge or task that can only be solved with the help of a caregiver, or perhaps an explicit prompt to work together [59].

Parents also helped children make connections between the digital media and other times and places in their own lives (i.e., boundary crossing). Although parents can and should initiate boundary crossing without prompting from apps [92], prompts that relate to everyday life or even a blank page create opportunities for boundary crossing. These connections can tap into experiences that are inherently interesting to children such as writing their own name [8] or, as seen in other work, investigating issues related to their community and presenting them to family and friends [6].

\subsection{Limitations \& Future Work}

There are a few directions for future work that would address the limitations of our study. First, more systematically analyzing a wider array of apps to evaluate how they fulfill JME guidelines could add to our initial assessment of children's apps. Second, our sample size and makeup did not permit comparisons of cultures or other groups. And, while not intended by our recruitment strategies, only mothers (not fathers or other caregivers) participated in the study. Because different caregivers likely value or approach JME differently [90], a future line of investigation is whether/how cultural differences or other variables underlie differences in families' approaches to playing together. Third, while this study allowed us to examine a current "best case scenario" of JME in a controlled setting with apps we chose, naturalistic research on families' play with touchscreen apps in the home would be a valuable next step. Finally, future work could translate the list of design recommendations into a more prescriptive tool with examples for designers.

\section{CONCLUSION}

Our investigation suggests that artistic creation apps, and CoCreation in general, are one promising avenue that parents with young children might choose when looking to play together. Key advantages of artistic creation apps are that they are user-paced and can be driven by child interest. With that said, joint engagement rarely happened without parents using key strategies, such maintaining shared positioning and turn-taking or providing cognitive and technical support that proved to be of interest to children. Encouraging children to make connections between the app play and their own lives was effective for getting children interested in joint play, too. Parents worked hard to find ways to be involved with their children's play with artistic creation apps, and design features could do more to help. Families may not have a lot of time to play together, but app design and parent strategies for JME could make families' attempts to play together more enjoyable, which would likely lead to more beneficial JME in the future.

\section{SELECTION AND PARTICIPATION OF CHILDREN}

All procedures were approved by an Institutional Review Board in accordance with the Belmont Report and guidance on ethical research from the United States Office for Human Research Protections. Participants were recruited using social media, word of mouth, and flyers distributed in Play and Learn group meetings, community centers, and libraries. Inclusion criteria were children had to be age 4 or 5 but not yet in kindergarten, and both parent and child had to have some prior experience using a touchscreen device. Participants also had to be proficient in speaking English. At the start of sessions, a researcher explained the study, and the parent read and signed a form, consenting to their own and their child's participation. The form explained the family could stop playing at any time and data collected would be kept confidential and stored securely. Researchers also obtained verbal assent from the child.

\section{ACKNOWLEDGMENTS}

The study team would like to thank all of the parents and children for their participation in this study. We also thank Alexis Hiniker and Emeline Brulé for their helpful feedback on this work.

\section{REFERENCES}

[1] AAP Council on Communications and Media. 2016. Media and young minds. Pediatrics 138, 5 (Nov. 2016). https://doi.org/10.1542/peds.2016-2591

[2] Pål André Aarsand. 2016. Computer and video games in family life: The digital divide as a resource in intergenerational interactions. Childhood (July 2016). https://doi.org/10.1177/0907568207078330

[3] Yasushi Akiyama and Sageev Oore. 2008. PlaceAndPlay: A digital tool for children to create and record music. In Proceedings of the SIGCHI Conference on Human Factors in Computing Systems (CHI '08). ACM, New York, NY, 735-738. https: //doi.org/10.1145/1357054.1357170

[4] Alissa N. Antle, Milena Droumeva, and Greg Corness. 2008. Playing with the sound maker: Do embodied metaphors help children learn?. In Proceedings of the 7 th International Conference on Interaction Design and Children (IDC '08). ACM, New York, NY, 178-185. https://doi.org/10.1145/1463689.1463754

[5] Zhen Bai, Alan F. Blackwell, and George Coulouris. 2015. Exploring expressive augmented reality: The FingAR Puppet system for social pretend play. In Proceedings of the 33rd Annual ACM Conference on Human Factors in Computing Systems (CHI '15). ACM, New York, NY, 1035-1044. https://doi.org/10.1145/ 2702123.2702250

[6] Brigid Barron and Amber Maria Levinson. 2018. Media as a catalyst for children's engagement in learning at home and across settings. In Children and Families in 
the Digital Age: Learning Together in a Media Saturated Culture, Elisabeth Gee, Lori M. Takeuchi, and Ellen Wartella (Eds.). Routledge, New York, NY, 17-36.

[7] Brigid Barron, Caitlin Kennedy Martin, Lori Takeuchi, and Rachel Fithian. 2009. Parents as learning partners in the development of technological fluency. International fournal of Learning and Media 1, 2 (May 2009), 55-77. https://doi.org/10.1162/ijlm.2009.0021

[8] Janet W. Bloodgood. 1999. What's in a name? Children's name writing and literacy acquisition. Reading Research Quarterly 34, 3 (1999), 342-367. https: //doi.org/10.1598/RRQ.34.3.5

[9] Elizabeth Bonsignore, Alexander J. Quinn, Allison Druin, and Benjamin B. Bederson. 2013. Sharing stories "in the wild": A mobile storytelling case study using StoryKit. ACM Transactions on Computer-Human Interaction 20, 3, Article 18 (July 2013), 38 pages. https://doi.org/10.1145/2491500.2491506

[10] Mindy Brooks, Ashley Fenwick-Naditch, and Erica Branch-Ridley. 2011. Electric Racer: An intergenerational gaming experience designed to promote literacy. In The New Coviewing: Designing for Learning through foint Media Engagement. The Joan Ganz Cooney Center at Sesame Workshop, New York, NY, 30-33.

[11] Cynthia Chiong and Carly Shuler. 2010. Learning: Is there an app for that? Investigations of young children's usage and learning with mobile devices and apps. Technical Report. The Joan Ganz Cooney Center at Sesame Workshop, New York. 34 pages.

[12] Dimitri A. Christakis. 2014. Interactive media use at younger than the age of 2 years: Time to rethink the American Academy of Pediatrics guideline? FAMA Pediatrics 168, 5 (May 2014), 399-400. https://doi.org/10.1001/jamapediatrics. 2013.5081

[13] Drew Cingel and Anne Marie Piper. 2017. How parents engage children in tabletbased reading experiences: An exploration of haptic feedback. In Proceedings of the 2017 ACM Conference on Computer Supported Cooperative Work and Social Computing (CSCW '17). ACM, New York, NY, 505-510. https://doi.org/10.1145/ 2998181.2998240

[14] Maayan Cohen, Kody R. Dillman, Haley MacLeod, Seth Hunter, and Anthony Tang. 2014. OneSpace: Shared visual scenes for active freeplay. In Proceedings of the SIGCHI Conference on Human Factors in Computing Systems (CHI '14). ACM, New York, NY, 2177-2180. https://doi.org/10.1145/2556288.2557117

[15] Sabrina L. Connell, Alexis R. Lauricella, and Ellen Wartella. 2015. Parental co-use of media technology with their young children in the USA. Fournal of Children and Media 9, 1 (Jan. 2015), 5-21. https://doi.org/10.1080/17482798.2015.997440

[16] Juliet Corbin and Anselm Strauss. 2008. Basics of Qualitative Research: Techniques and Procedures for Developing Grounded Theory (3rd. ed. ed.). SAGE Publications, Inc, Thousand Oaks, CA. https://doi.org/10.4135/9781452230153

[17] Edward Deci and Richard M. Ryan. 1985. Intrinsic Motivation and SelfDetermination in Human Behavior. Springer US. https://doi.org/10.1007/978-14899-2271-7

[18] Sharon J. Derry, Roy D. Pea, Brigid Barron, Randi A. Engle, Frederick Erickson, Ricki Goldman, Rogers Hall, Timothy Koschmann, Jay L. Lemke, Miriam Gamoran Sherin, and Bruce L. Sherin. 2010. Conducting video research in the learning sciences: Guidance on selection, analysis, technology, and ethics. Fournal of the Learning Sciences 19, 1 (Jan. 2010), 3-53. https://doi.org/10.1080/ 10508400903452884

[19] Nicoletta Di Blas and Bianca Boretti. 2009. Interactive storytelling in pre-school: A case-study. In Proceedings of the 8th International Conference on Interaction Design and Children (IDC '09). ACM, New York, NY, 44-51. https://doi.org/10. 1145/1551788.1551797

[20] Raphael M. Diaz, Cynthia J. Neal, and Marina Amaya-Williams. 1992. The social origins of self-regulation. In Vygotsky and Education: Instructional Implications and Applications of Sociohistorical Psychology, Luis C. Moll (Ed.). Cambridge University Press, New York, NY, 127-154.

[21] Carrie A. Ewin, Andrea E. Reupert, Louise A. McLean, and Christopher J. Ewin. 2020. The impact of joint media engagement on parent-child interactions: A systematic review. Human Behavior and Emerging Technologies n/a, n/a (2020). https://doi.org/10.1002/hbe2.203

[22] Jerry Alan Fails, Allison Druin, and Mona Leigh Guha. 2010. Mobile collaboration: Collaboratively reading and creating children's stories on mobile devices. In Proceedings of the 9th International Conference on Interaction Design and Children (IDC '10). ACM, New York, NY, 20-29. https://doi.org/10.1145/1810543.1810547

[23] Shalom M. Fisch, Anna Akerman, Melissa Morgenlander, Susan K. McCann Brown, Susan R. D. Fisch, Bena B. Schwartz, and Pat Tobin. 2008. Coviewing preschool television in the US. Journal of Children and Media 2, 2 (July 2008), 163-173. https://doi.org/10.1080/17482790802078680

[24] Sean Follmer, Hayes Raffle, Janet Go, Rafael Ballagas, and Hiroshi Ishii. 2010 Video play: Playful interactions in video conferencing for long-distance families with young children. In Proceedings of the 9th International Conference on Interaction Design and Children (IDC '10). ACM, New York, NY, 49-58. https://doi.org/10.1145/1810543.1810550

[25] Kenneth R. Ginsburg, the Committee on Communications, and the Committee on Psychosocial Aspects of Child and Family Health. 2007. The importance of play in promoting healthy child development and maintaining strong parent-child bonds Pediatrics 119, 1 (Jan. 2007), 182-191. https://doi.org/10.1542/peds.2006-2697
[26] Terrell Glenn, Ananya Ipsita, Caleb Carithers, Kylie Peppler, and Karthik Ramani. 2020. StoryMakAR: Bringing stories to life with an augmented reality \& physical prototyping toolkit for youth. In Proceedings of the 2020 CHI Conference on Human Factors in Computing Systems (CHI '20). ACM, New York, NY, 1-14. https: //doi.org/10.1145/3313831.3376790

[27] Wendy S. Grolnick, Edward L. Deci, and Richard M. Ryan. 1997. Internalization within the family: The self-determination theory perspective. In Parenting and Children's Internalization of Values: A Handbook of Contemporary Theory, Joan E. Grusec and Leon Kuczynski (Eds.). John Wiley \& Sons Inc., Hoboken, NJ, 135-161.

[28] Wendy S. Grolnick and Eva M. Pomerantz. 2009. Issues and challenges in studying parental control: Toward a new conceptualization. Child Development Perspectives 3, 3 (Nov. 2009), 165-170. https://doi.org/10.1111/j.1750-8606.2009.00099.x

[29] Lisa Guernsey. 2012. Screen Time: How Electronic Media-From Baby Videos to Educational Software-Affects Your Young Child. Hachette Book Group, New York, NY.

[30] Megan K. Halpern, Jakob Tholander, Max Evjen, Stuart Davis, Andrew Ehrlich, Kyle Schustak, Eric P.S. Baumer, and Geri Gay. 2011. MoBoogie: Creative expression through whole body musical interaction. In Proceedings of the SIGCHI Conference on Human Factors in Computing Systems (CHI '11). ACM, New York, NY, 557-560. https://doi.org/10.1145/1978942.1979020

[31] Idit Harel and Seymour Papert (Eds.). 1991. Constructionism. Ablex Publishing, Westport, CT.

[32] Alexis Hiniker, Bongshin Lee, Julie A. Kientz, and Jenny S. Radesky. 2018. Let's play! Digital and analog play between preschoolers and parents. In Proceedings of the 2018 CHI Conference on Human Factors in Computing Systems (CHI '18). ACM, New York, NY, 1-13. https://doi.org/10.1145/3173574.3174233

[33] Alexis Hiniker, Bongshin Lee, Kiley Sobel, and Eun Kyoung Choe. 2017. Plan \& play: Supporting intentional media use in early childhood. In Proceedings of the 2017 Conference on Interaction Design and Children. ACM, New York, NY, 85-95. https://doi.org/10.1145/3078072.3079752

[34] Kathy Hirsh-Pasek, Jennifer M. Zosh, Roberta Michnick Golinkoff, James H. Gray, Michael B. Robb, and Jordy Kaufman. 2015. Putting education in "educational" apps: Lessons from the science of learning. Psychological Science in the Public Interest (April 2015). https://doi.org/10.1177/1529100615569721

[35] Anthony J. Hornof and Anna Cavender. 2005. EyeDraw: Enabling children with severe motor impairments to draw with their eyes. In Proceedings of the SIGCHI Conference on Human Factors in Computing Systems (CHI '05). ACM, New York, NY, 161. https://doi.org/10.1145/1054972.1054995

[36] Heather A. Horst. 2009. Families. In Hanging Out, Messing Around, and Geeking Out: Kids Living and Learning with New Media (1st ed.). The MIT Press, Cambridge, MA, 149-194.

[37] Juan Pablo Hourcade. 2015. Child development. In Child-Computer Interaction (first ed.). Self, 7-20.

[38] Juan Pablo Hourcade. 2015. Creativity and problem solving. In Child-Computer Interaction (first ed.). Self, 60-76.

[39] Juan Pablo Hourcade, Benjamin B. Bederson, Allison Druin, and Gustav Taxén. 2002. KidPad: Collaborative storytelling for children. In CHI '02 Extended Abstracts on Human Factors in Computing Systems (CHI EA '02). ACM, New York, NY, 500501. https://doi.org/10.1145/506443.506449

[40] Sara Isola and Jerry Alan Fails. 2012. Family and design in the IDC and CHI communities. In Proceedings of the 11th International Conference on Interaction Design and Children (IDC '12). ACM, New York, NY, 40-49. https://doi.org/10. 1145/2307096.2307102

[41] Sam Jacoby and Leah Buechley. 2013. Drawing the electric: Storytelling with conductive ink. In Proceedings of the 12th International Conference on Interaction Design and Children (IDC '13). ACM, New York, NY, 265-268. https://doi.org/10. $1145 / 2485760.2485790$

[42] Gail Jefferson. 2004. Glossary of transcript symbols with an introduction. In Conversation Analysis: Studies from the First Generation, Gene H. Lerner (Ed.). John Benjamins Publishing Company, Amsterdam/Philadelphia, 13-34. https: //benjamins.com/catalog/pbns.125.02jef

[43] Brigitte Jordan and Austin Henderson. 1995. Interaction analysis: Foundations and practice. Fournal of the Learning Sciences 4, 1 (Jan. 1995), 39-103. https: //doi.org/10.1207/s15327809jls0401_2

[44] Saba Kawas, Ye Yuan, Akeiylah DeWitt, Qiao Jin, Susanne Kirchner, Abigail Bilger, Ethan Grantham, Julie A Kientz, Andrea Tartaro, and Svetlana Yarosh. 2020. Another decade of IDC research: Examining and reflecting on values and ethics. In Proceedings of the Interaction Design and Children Conference (London, United Kingdom) (IDC '20). Association for Computing Machinery, New York, NY, USA, 205-215. https://doi.org/10.1145/3392063.3394436

[45] Bogyeong Kim, Chaeeun Lee, Jung Huh, and Woohun Lee. 2020. Puppet book: Digital storybook with back-of-device puppeteering interface for parent and child. In Extended Abstracts of the 2020 CHI Conference on Human Factors in Computing Systems (CHI EA '20). ACM, New York, NY, 1-4. https://doi.org/10. $1145 / 3334480.3383175$

[46] Marina Krcmar and Drew P. Cingel. 2014. Parent-child joint reading in traditional and electronic formats. Media Psychology 17, 3 (July 2014), 262-281. https: //doi.org/10.1080/15213269.2013.840243 
[47] Alexis R. Lauricella, Rachel Barr, and Sandra L. Calvert. 2014. Parent-child interactions during traditional and computer storybook reading for children's comprehension: Implications for electronic storybook design. International fournal of Child-Computer Interaction 2, 1 (Jan. 2014), 17-25. https://doi.org/10.1016/ j.ijcci.2014.07.001

[48] Amber Maria Levinson and Brigid Barron. 2018. Latino immigrant families learning with digital media across settings and generations. Digital Education Review 0, 33 (June 2018), 150-169. https://doi.org/10.1344/der.2018.33.150-169

[49] Duri Long, Hannah Guthrie, and Brian Magerko. 2018. Don't steal my balloons: Designing for musical adult-child ludic engagement. In Proceedings of the 17th ACM Conference on Interaction Design and Children (IDC '18). ACM, New York, NY, 657-662. https://doi.org/10.1145/3202185.3210795

[50] Michelle Margaret Neumann. 2015. Young children and screen time: Creating a mindful approach to digital technology. Australian Educational Computing 30, 2 (Dec. 2015). http://journal.acce.edu.au/index.php/AEC/article/view/67

[51] Michelle M. Neumann. 2016. Young children's use of touch screen tablets for writing and reading at home: Relationships with emergent literacy. Computers \& Education 97 (June 2016), 61-68. https://doi.org/10.1016/j.compedu.2016.02.013

[52] Michelle M. Neumann. 2018. Parent scaffolding of young children's use of touch screen tablets. Early Child Development and Care 188, 12 (Dec. 2018), 1654-1664. https://doi.org/10.1080/03004430.2016.1278215

[53] Tiffany A. Pempek and Alexis R. Lauricella. 2017. The effects of parent-child interaction and media use on cognitive development in infants, toddlers, and preschoolers. In Cognitive Development in Digital Contexts, Fran C. Blumberg and Patricia J. Brooks (Eds.). Academic Press, London, UK, 53-74.

[54] Pew Research Center. 2019. Smartphone ownership is growing rapidly around the world, but not always equally. Technical Report. Pew Research Center.

[55] Becky Pham and Sun Sun Lim. 2019. Vietnamese pre-schoolers' tablet use and early childhood learning: an ecological investigation. Fournal of Children and Media 13, 3 (July 2019), 241-259. https://doi.org/10.1080/17482798.2019.1613247

[56] Jean Piaget and Barbel Inhelder. 1969. The Psychology of the Child. Basic Books, New York, NY.

[57] Robert C. Pianta, Nicholas Smith, and Ronald E. Reeve. 1991. Observing mother and child behavior in a problem-solving situation at school entry: Relations with classroom adjustment. School Psychology Quarterly 6, 1 (1991), 1-15. https //doi.org/10.1037/h0088238

[58] Alexander J Quinn, Benjamin B. Bederson, Elizabeth M. Bonsignore, and Allison Druin. 2009. StoryKit: Designing a mobile application for story creation by children and older adults. Technical Report Tech. rep. HCIL-2009-22. Human Computer Interaction Lab, University of Maryland, College Park, MD. 11 pages.

[59] Hayes Raffle, Rafael Ballagas, Glenda Revelle, Hiroshi Horii, Sean Follmer, Janet Go, Emily Reardon, Koichi Mori, Joseph Kaye, and Mirjana Spasojevic. 2010 Family story play: Reading with young children (and Elmo) over a distance. In Proceedings of the SIGCHI Conference on Human Factors in Computing Systems (CHI '10). ACM, New York, NY, 1583-1592. https://doi.org/10.1145/1753326.1753563

[60] Hayes Raffle, Cati Vaucelle, Ruibing Wang, and Hiroshi Ishii. 2007. Jabberstamp Embedding sound and voice in traditional drawings. In Proceedings of the 6th International Conference on Interaction Design and Children (IDC '07). ACM, New York, NY, 137-144. https://doi.org/10.1145/1297277.1297306

[61] Stephanie M. Reich, Ksenia A. Korobkova, Rebecca W. Black, and Mariya Sumaroka. 2013. "Hey! Can you show me how to do this?": Digital games mediating family interactions. In Children's Virtual Play Words: Culture, Learning, and Participation, Anne Burke and Jackie Marsh (Eds.). Peter Lang Inc., New York, NY, 133-150.

[62] Glenda Revelle and Jennifer Bowman. 2017. Parent-child dialogue with eBooks In Proceedings of the 2017 Conference on Interaction Design and Children (IDC '17) ACM, New York, NY, 346-351. https://doi.org/10.1145/3078072.3079753

[63] Victoria Rideout. 2017. The Common Sense Census: Media Use by Kids Age Zero to Eight. Technical Report. Common Sense Media, San Francisco, CA. https://www.commonsensemedia.org/sites/default/files/uploads/research/ csm_zerotoeight_fullreport_release_2.pdf

[64] Victoria Rideout and Michael B. Robb. 2020. The Common Sense census: Media use by kids age zero to eight, 2020. Technical Report. Common Sense Media, San Francisco, CA. https://www.commonsensemedia.org/sites/default/files/uploads/ research/2020_zero_to_eight_census_final_web.pdf

[65] Barbara Rogoff. 2003. The Cultural Nature of Human Development. Oxford University Press, New York, NY.

[66] Elisa Rubegni and Monica Landoni. 2014. Fiabot!: Design and evaluation of a mobile storytelling application for schools. In Proceedings of the 2014 Conference on Interaction Design and Children (IDC '14). ACM, New York, NY, 165-174. https://doi.org/10.1145/2593968.2593979

[67] Kimiko Ryokai, Stefan Marti, and Hiroshi Ishii. 2004. I/O Brush: Drawing with everyday objects as ink. In Proceedings of the 2004 Conference on Human Factors in Computing Systems (CHI '04). ACM, New York, NY, 303-310. https://doi.org/ $10.1145 / 985692.985731$

[68] Sago Sago Toys Inc. 2014. Sago Mini Doodlecast. https://apps.apple.com/us/ app/sago-mini-doodlecast/id469487373
[69] Herman Saksono, Ashwini Ranade, Geeta Kamarthi, Carmen Castaneda-Sceppa, Jessica A. Hoffman, Cathy Wirth, and Andrea G. Parker. 2015. Spaceship Launch: Designing a collaborative exergame for families. In Proceedings of the 18th ACM Conference on Computer Supported Cooperative Work \& Social Computing (CSCW '15). ACM, New York, NY, 1776-1787. https://doi.org/10.1145/2675133.2675159

[70] Jordan Shapiro. 2018. The New Childhood: Raising Kids to Thrive in a Connected World. Little, Brown Spark, New York, NY

[71] Sinem Siyahhan and Elisabeth Gee. 2018. Families at Play: Connecting and Learning through Video Games. MIT Press, Cambridge, MA.

[72] Petr Slovák, Kael Rowan, Christopher Frauenberger, Ran Gilad-Bachrach, Mia Doces, Brian Smith, Rachel Kamb, and Geraldine Fitzpatrick. 2016. Scaffolding the scaffolding: Supporting children's social-emotional learning at home. In Proceedings of the 19th ACM Conference on Computer-Supported Cooperative Work \& Social Computing (CSCW' '16). ACM, New York, NY, 1751-1765. https://doi. org $/ 10.1145 / 2818048.2820007$

[73] Kiley Sobel, Arpita Bhattacharya, Alexis Hiniker, Jin Ha Lee, Julie A. Kientz, and Jason C. Yip. 2017. It wasn't really about the Pokémon: Parents' perspectives on a location-based mobile game. In Proceedings of the 2017 CHI Conference on Human Factors in Computing Systems (CHI '17). ACM, New York, NY, 1483-1496. https://doi.org/10.1145/3025453.3025761

[74] Kiley Sobel, Kate Yen, Yi Cheng, Yeqi Chen, and Alexis Hiniker. 2019. No touch pig! Investigating child-parent use of a system for training executive function. In Proceedings of the 18th ACM International Conference on Interaction Design and Children (IDC '19). ACM, New York, NY, 339-351. https://doi.org/10.1145/ 3311927.3323132

[75] Reed Stevens and William R. Penuel. 2010. Studying and fostering learning through joint media engagement. In Principal Investigators Meeting of the National Science Foundation's Science of Learning Centers, October, Arlington, VA. Arlington, VA, 1-75.

[76] Morton Subotnik. 2017. Mort Subotnik's Pitch Painter. https://apps.apple.com/ us/app/mort-subotnicks-pitch-painter/id519738403

[77] Lori Takeuchi and Reed Stevens. 2011. The New Coviewing: Designing for Learning through foint Media Engagement. Technical Report. The Joan Ganz Cooney Center at Sesame Workshop, New York.

[78] Catherine S. Tamis-LeMonda and Marc H. Bornstein. 1989. Habituation and maternal encouragement of attention in infancy as predictors of toddler language, play, and representational competence. Child Development 60, 3 (June 1989), 738751. https://doi.org/10.2307/1130739

[79] Catherine S. Tamis-LeMonda, Jacqueline D. Shannon, Natasha J. Cabrera, and Michael E. Lamb. 2004. Fathers and mothers at play with their 2- and 3-year-olds: Contributions to language and cognitive development. Child Development 75, 6 (Nov. 2004), 1806-1820. https://doi.org/10.1111/j.1467-8624.2004.00818.x

[80] The Joan Ganz Cooney Center. 2015. Family Time with Apps: A Guide to Using Apps With Your Kids. Technical Report. The Joan Ganz Cooney Center at Sesame Workshop, New York. http://joanganzcooneycenter.org/wp-content/uploads/ 2015/08/jgcc_familytimewithapps.pdf

[81] Yvonne Vezzoli, Sara Kalantari, Natalia Kucirkova, and Asimina Vasalou. 2020. Exploring the design space for parent-child reading. In Proceedings of the 2020 CHI Conference on Human Factors in Computing Systems (CHI '20). ACM, New York, NY, 1-12. https://doi.org/10.1145/3313831.3376696

[82] Lev S. Vygotsky. 1978. Mind in Society: The Development of Higher Psychological Processes. Harvard University Press, Cambridge, MA.

[83] Torben Wallbaum, Andrii Matviienko, Swamy Ananthanarayan, Thomas Olsson, Wilko Heuten, and Susanne C.J. Boll. 2018. Supporting communication between grandparents and grandchildren through tangible storytelling systems. In Proceedings of the 2018 CHI Conference on Human Factors in Computing Systems (CHI '18). ACM, New York, NY, 1-12. https://doi.org/10.1145/3173574.3174124

[84] Ron Warren. 2003. Parental mediation of preschool children's television viewing. Journal of Broadcasting \& Electronic Media 47, 3 (Sept. 2003), 394-417. https: //doi.org/10.1207/s15506878jobem4703_5

[85] Eileen Wood, Marjan Petkovski, Domenica De Pasquale, Alexandra Gottardo, Mary Ann Evans, and Robert S. Savage. 2016. Parent scaffolding of young children when engaged with mobile technology. Frontiers in Psychology 7 (May 2016). https://doi.org/10.3389/fpsyg.2016.00690

[86] Svetlana Yarosh. 2008. Supporting parent-child interaction in divorced families. In Proceedings of the 7th International Conference on Interaction Design and Children (IDC '08). ACM, New York, NY, 33-36. https://doi.org/10.1145/1463689.1463711

[87] Svetlana Yarosh, Iulian Radu, Seth Hunter, and Eric Rosenbaum. 2011. Examining values: An analysis of nine years of IDC research. In Proceedings of the Interaction Design and Children Conference (Ann Arbor, Michigan) (IDC '11). Association for Computing Machinery, New York, NY, USA, 136-144. https://doi.org/10.1145/ 1999030.1999046

[88] Svetlana Yarosh, Anthony Tang, Sanika Mokashi, and Gregory D. Abowd. 2013. "Almost touching": Parent-child remote communication using the ShareTable system. In Proceedings of the 2013 Conference on Computer Supported Cooperative Work (CSCW'13). ACM, New York, NY, 181-192. https://doi.org/10.1145/2441776. 2441798 
[89] Nicola Yelland and Jennifer Masters. 2007. Rethinking scaffolding in the in formation age. Computers \& Education 48, 3 (April 2007), 362-382. https: //doi.org/10.1016/j.compedu.2005.01.010

[90] Kate Yen, Yeqi Chen, Yi Cheng, Sijin Chen, Ying-Yu Chen, Yiran Ni, and Alexis Hiniker. 2018. Joint media engagement between parents and preschoolers in the U.S., China, and Taiwan. Proceedings of the ACM on Human-Computer Interaction 2, CSCW, Article 192 (Nov. 2018), 19 pages. https://doi.org/10.1145/3274461
[91] Junnan Yu, Chenke Bai, and Ricarose Roque. 2020. Considering parents in coding kit design: Understanding parents' perspectives and roles. In Proceedings of the 2020 CHI Conference on Human Factors in Computing Systems (CHI '20). ACM, New York, NY, 1-14. https://doi.org/10.1145/3313831.3376130

[92] Andrea A. Zevenbergen and Grover J. Whitehurst. 2003. Dialogic reading: A shared picture book reading intervention for preschoolers. In On Reading Books to Children: Parents and Teachers, Anne van Kleeck, Steven A. Stahl, and Eurydice B. Bauer (Eds.). Routledge, London, UK, 177-200. 